Meta

Journal des traducteurs

Translators' Journal

\title{
Emotional Intelligence and Translation Studies: A New Bridge
}

\section{Séverine Hubscher-Davidson}

Volume 58, numéro 2, août 2013

URI : https://id.erudit.org/iderudit/1024177ar

DOI : https://doi.org/10.7202/1024177ar

Aller au sommaire du numéro

\section{Éditeur(s)}

Les Presses de l’Université de Montréal

ISSN

0026-0452 (imprimé)

1492-1421 (numérique)

Découvrir la revue

Citer cet article

Hubscher-Davidson, S. (2013). Emotional Intelligence and Translation Studies: A New Bridge. Meta, 58(2), 324-346. https://doi.org/10.7202/1024177ar

\section{Résumé de l'article}

Le présent article cherche à promouvoir l'étude de processus psychologiques non cognitifs en traductologie. Plus particulièrement, il a pour but de souligner l'importance d'étudier l'intelligence émotionnelle des traducteurs et interprètes. Nous définirons d'abord le concept d'intelligence émotionnelle et présenterons certaines études pertinentes dans le domaine en portant une attention particulière à deux d'entre elles. Nous examinerons ensuite des études menées récemment en traductologie et dans des disciplines connexes, lesquelles démontrent l'importance d'étudier les traits affectifs et émotionnels des traducteurs. Enfin, nous formulerons, dans la dernière section, des recommandations relatives à l'étude de l'intelligence émotionnelle en traductologie au profit de la communauté de traducteurs et d'interprètes. Nous démontrerons au passage l'utilité et la nécessité d'effectuer des recherches plus poussées sur les personnalités et l'intelligence émotionnelle des traducteurs et interprètes en vue d'approfondir la compréhension des processus de traduction et d'interprétation.
Ce document est protégé par la loi sur le droit d'auteur. L’utilisation des services d’Érudit (y compris la reproduction) est assujettie à sa politique d'utilisation que vous pouvez consulter en ligne.

https://apropos.erudit.org/fr/usagers/politique-dutilisation/ 


\title{
Emotional Intelligence and Translation Studies: A New Bridge
}

\author{
SÉVERINE HUBSCHER-DAVIDSON \\ Aston University, Birmingham, UK \\ s.hubscher-davidson@aston.ac.uk
}

\begin{abstract}
RÉSUMÉ
Le présent article cherche à promouvoir l'étude de processus psychologiques non cognitifs en traductologie. Plus particulièrement, il a pour but de souligner l'importance d'étudier l'intelligence émotionnelle des traducteurs et interprètes. Nous définirons d'abord le concept d'intelligence émotionnelle et présenterons certaines études pertinentes dans le domaine en portant une attention particulière à deux d'entre elles. Nous examinerons ensuite des études menées récemment en traductologie et dans des disciplines connexes, lesquelles démontrent l'importance d'étudier les traits affectifs et émotionnels des traducteurs. Enfin, nous formulerons, dans la dernière section, des recommandations relatives à l'étude de l'intelligence émotionnelle en traductologie au profit de la communauté de traducteurs et d'interprètes. Nous démontrerons au passage l'utilité et la nécessité d'effectuer des recherches plus poussées sur les personnalités et l'intelligence émotionnelle des traducteurs et interprètes en vue d'approfondir la compréhension des processus de traduction et d'interprétation.
\end{abstract}

\section{ABSTRACT}

This paper presents a case for the study of non-cognitive psychological processes in Translation Studies (TS). More specifically, it aims to highlight the value of studying the emotional intelligence (EI) of translators and interpreters. Firstly, the concept of EI is defined and a review of trait El profiling is undertaken, with a focus on two recent studies that have relevance for TS. Secondly, recent research within TS and related disciplines that provides evidence of the value of studying the affective and emotional traits of translators and interpreters is discussed. The final section of this paper provides some recommendations for the study of $\mathrm{El}$ in TS research to benefit the translation and interpreting community. It will be argued that investigating emotional intelligence is both necessary and desirable to gain a deeper understanding of translation and interpreting processes.

\section{MOTS-CLÉS/KEYWORDS}

psychologie, intelligence émotionnelle, caractéristiques individuelles, processus de traduction, personnalité.

psychology, emotional intelligence, individual differences, translation process, personality.

\section{Introduction}

Research of a psychological nature has gained a lot of ground in Translation Studies (TS) over the last few decades. The interdisciplinary nature of the field has naturally rendered it prone to borrowing (Brownlie 2008: 338) and research in cognitive science has, for example, informed the study of translation processes as evidenced by the recent proliferation of publications that bridge these disciplines (see for example Papavassiliou 2007; Bergen 2009; Shreve and Angelone 2010; Chmiel 2010, etc.). As 
Hatzidaki (2007: 14) aptly puts it, "given that the focus of research in translatology is the observation and analysis of language processing in translation, it becomes evident that psycholinguistics and translatology are interconnected." There are, however, other areas of psychology that have arguably not been given nearly as much attention within TS practice and research, and that therefore remain under-researched. Despite increasing acknowledgement that emotional aspects of translator behaviour may have an influence on translation performance (Jääskeläinen 1999; Hansen 2005; Hubscher-Davidson 2009) this aspect of the translation process has lacked visibility in the literature. A search for the term "emotional intelligence" in the John Benjamins Translation Studies Bibliography (11 August 2011) returned 0 hits. A further search for the word "emotion" returned a mere 27 hits, and a search for "personality" returned a total of 68 hits. The majority of results are concerned with the translation of emotional material or emotive language (see Hiirikoski 2002; Lee 2003; Wittwer 2007; Mohammady 2008), with only a handful addressing the personalities or emotions of translators and interpreters. Yet, there are increasing calls within the TS community to study the behaviours of these mediators and to raise awareness to their working processes (see Chesterman 1997; Hönig 1998; Hubscher-Davidson 2007; Alvstad, Hild et al. 2011). This increased visibility and recognition (Venuti 1995) has resulted in a shift of the object of study from translations to translators (Munday 2008a: 15), led to the creation of new links with other disciplines (e.g. sociology, cultural studies) and enabled the integration of new perspectives into the interdiscipline that is TS. As argued in this paper, however, areas such as emotional intelligence and personalities remain under-researched and could usefully be incorporated into TS to bring to light a wide range of issues and a new understanding of how translators and interpreters operate.

This article therefore aims to highlight the value of studying the emotional intelligence (EI) of today's translating and interpreting students and practitioners. Firstly, the concept of EI will be defined and a review of trait EI profiling will be undertaken, with a focus on two recent non-cognitive studies in Psychology that have relevance for Translation Studies. Secondly, recent research within TS and related disciplines that provides evidence of the value of studying the affective and emotional traits of translators and interpreters will be discussed. The final section of this paper will provide some recommendations for the study of EI in TS research to benefit the translation and interpreting community. It will be argued that investigating emotional intelligence is both necessary and desirable to gain a deeper understanding of translation and interpreting processes.

\section{Defining Emotional Intelligence: Trait and Ability Models}

The study of emotions is not a new field of enquiry, and has been the subject of considerable scientific research since Publilius Syrus wrote in the first century B.C. "rule your feelings, let your feelings rule you" (Syrus c.100BC/1961 in Salovey and Mayer 1990/2004: 2). Since then, the study of emotions has generated much popular interest, often to the dismay of psychologists who speak of an uneasy tension between the world of popular psychology, and painstaking research (Mayer and Ciarrochi 2006: $\mathrm{xv})$. The result of this popularization of the field is a great diversity of definitions and approaches, and the study of emotions continues to be the focus of emotional intel- 
ligence researchers attempting to find critical and valid answers to the question: why do we act or behave the way we do? According to Salovey and Mayer, emotions can be defined as such:

Emotions are organized responses, crossing the boundaries of many psychological subsystems, including the physiological, cognitive, motivational, and experiential systems. Emotions typically arise in response to an event, either internal or external, that has a positively or negatively valenced meaning for the individual. (Salovey and Mayer 1990/2004: 2)

The concept of emotional intelligence first emerged in the eighties as part of Gardner's view of social intelligence, the first of its kind to suggest that there are seven types of intelligence, including interpersonal intelligence, the ability to understand other people, and intrapersonal intelligence, the ability to understand yourself and develop a sense of your own identity (Gardner 1983). Gardner's work on these new intelligences was the inspiration for many psychological studies on how people appraise and communicate emotions, and how they use these to solve problems. Research on emotional intelligence is said to differ from research on cognition and affect because it "concentrates not on memory or judgement per se, but on more general contributions of emotionality to personality" (Salovey and Mayer 1990/2004: 6). The emphasis on non-cognitive factors was a departure from more traditional conceptualizations of intelligence. In 1990, Salovey and Mayer drew together much of the disparate research on emotional intelligence and developed a formal theory of the concept. They defined the emotional intelligence construct as "the ability to monitor one's own and others' feelings and emotions, to discriminate among them and to use this information to guide one's thinking and actions" (Salovey and Mayer 1990/2004: 189). Since then, two separate and un-related conceptualisations of EI have developed. It is now widely accepted that EI can either be conceptualised as a lower level personality trait, known as trait EI, or as a type of cognitive intelligence, known as ability EI (Williams, Daley et al. 2010). Researchers distinguish between these two EI constructs, depending on whether the operationalization process is based on self-report (e.g. personality questionnaires) or on maximum performance, such as IQ tests (Petrides, Pita et al. 2007).

According to Petrides, Pita et al. (2007: 283), trait EI, also known as trait emotional self-efficacy, is a distinct compound construct and a constellation of emotional self-perceptions located at the lower levels of personality hierarchies. As it concerns emotion-related dispositions and self-perceptions, it is best measured via self-report. On the other hand, the authors postulate that ability EI (or cognitive-emotional ability) concerns emotion-related cognitive abilities that are best measured via performance-based tests. Whereas the ability models relate more specifically to mental skills, trait models measure a number of personality qualities or traits (Petrides and Furnham 2001).

Brackett and Geher (2006: 28) claim that adherents to both schools of thought have developed tests to measure EI that correspond to their own conceptualisations, thus leading to the creation of two distinct test-types measuring emotion-relevant abilities (for ability-models), and perceptions of emotions (for trait models). Whether EI is considered an ability or a trait therefore entails a different type of measurement, and scholars interested in exploring the emotional intelligence of translators would need to reflect on whether successful performance in translation can/should be 
attributed to a student's ability to process emotional information, and whether this then could actually be usefully evaluated by measures of self-perceptions of their ability to recognize emotion-laden information.

In any case, problems have been reported with measures pertaining to both aforementioned models (Cooper 2002; Ciarrochi, Forgas et al. 2006; Matthews, Deary et al. 2003; Fiori and Antonakis 2011), and each has its supporters. Many scholars (Kaufman and Kaufman 2001; Van Rooy and Viswesvaran 2004; Mayer 2006) favour the so-called more objective ability testing measures as opposed to the self-report inventories, which, they argue, carry the risk of faked responses. On the other hand, Petrides, Frederickson et al. (2004) suggest that the measurement of ability EI remains challenging. It has been argued that ability EI measures assess emotion-related knowledge, rather than performance (Williams, Daley et al. 2009: 317), and that the operationalization of ability EI is problematic because the subjectivity of emotional experience undermines the development of IQ-like tests (Petrides, Pita et al. 2007). Trait EI is said to be more straightforward to assess, and to "enjoy widespread empirical support and consistently replicated findings from numerous studies that are theoretically driven, methodologically sophisticated, and independently conducted" (Petrides 2010: 138). Petrides, Frederickson et al. (2004: 278) acknowledge, however, that research in the field has produced mixed results, and that "the quantity of empirical work carried out on the construct, including the development of appropriate measures, seems to bear an inverse relationship to the interest it has attracted." Despite the presence of distinct perspectives on how to study EI and the need for further empirical work, findings from studies carried out in the field can still be of interest to the TS community.

In the next section, I will provide a brief critical overview of trait EI profiling research before discussing two specific studies that have made use of trait EI measurements in higher education contexts and their relevance for translating and interpreting.

\section{Trait EI Profiling}

On account of the current validity and psychometric problems associated with the ability perspective (Mikolajczak, Roy et al. 2009: 699) and the potential relevance of trait EI for TS, the present paper focuses on the trait EI perspective. Research on trait EI has gathered significant momentum over the last few years. According to Petrides, Vernon et al. (2011: 35), trait EI provides a comprehensive operationalization of the affective aspects of personality, and the key benefits of trait EI theory are to be found in conceptual content and explanatory power (Petrides 2009b). According to Mikolajczak, Roy et al. (2009: 700), evidence suggests that trait EI is fertile from both explicative and predictive standpoints. For instance, trait EI is strongly predictive of emotional and social criteria and correlates strongly with affect-laden variables (Mavroveli, Petrides et al. 2009: 268).

Trait models consider EI as a multifaceted construct with 13-15 emotion-related behavioural dispositions that are thought to affect the ways individuals cope with demands and pressures (Nelis, Quoidbach et al. 2009). There are several good measures of trait EI that are said to provide comprehensive coverage of the sampling domain, present a stable factor structure across studies, and show excellent psycho- 
metric properties (Petrides, Vernon et al. 2011: 37). In their study of the psychometric properties of a particular trait EI measure, Mikolajczak, Luminet et al. (2007) highlight the relevance of trait EI for professions with an affective component and its particular relevance for differentiating between successful and unsuccessful students in education. The construct is said to be useful because it organizes the main individual differences in affectivity under a single framework (Mikolajczak, Roy et al. 2009).

A large number of studies have documented a positive association between trait EI and well-being related variables (e.g. Petrides, Pita et al. 2007; Cordovil de Sousa Uva, De Timary et al. 2009; Mikolajczak, Petrides et al. 2009) and trait EI has been found to significantly moderate responses to stress (e.g. Mikolajczak and Luminet 2008; Mikolajczak, Menil et al. 2007). Student academic commitment and success have been related to trait EI (e.g. Jaeger 2003) as well as team performance and group cohesiveness (e.g. Quoidbach and Hansenne 2009). According to Mikolajczak, Bodarwé et al. 2010, higher trait EI scores have also been associated with a lower risk for mental disorders, such as depression and anxiety. These authors have also recently discovered that individuals with higher trait EI evidence greater resting left frontal activation, which is associated with higher extraversion, social competence and enhanced emotion regulation abilities (Mikolajczak, Bodarwé et al. 2010). Individuals with high trait EI are more prone to use problem-focused rather than avoidance coping strategies (Petrides, Pita et al. 2007), to appraise situations as challenging rather than threatening (Mikolajczak, Luminet et al. 2007), and to be more creative, with high sensitivity in particular being a requirement for creative work (Sánchez-Ruiz, Hernández-Torrano et al. 2011). Interestingly, high levels of trait EI are also said to predispose individuals to think and act in ways that encourage positive and discourage negative emotional experiences (Mikolajczak, Menil et al. 2007).

Trait EI measures show robust empirical evidence of criterion validity, and offer strong predictive power (Joseph and Newman 2010). Non-cognitive variables such as personality and emotional aspects have attracted the interest of scholars who made use of trait EI theory as the main reference framework in areas as diverse as alcohol dependency and craving (Cordovil de Sousa Uva, De Timary et al. 2009), leadership effectiveness (Villanueva and Sánchez 2007), emotional labour styles in nursing (Mikolajczak, Menil et al. 2007) and mental health (Mikolajczak, Luminet et al. 2007). In fact, a vast amount of research has documented a significant and robust association between trait EI and mental health, and studies in this area have explored the moderating effects of trait EI on mood deterioration in response to acute, intermediary and chronic stressors in both experimental and lab-based conditions, the results of which indicate that individuals with high EI demonstrate a recurring resilience in response to life stressors (Mikolajczak, Petrides et al. 2009).

Despite these valuable findings, a number of limitations may be worth highlighting in relation to psychometric studies, and to trait EI studies in particular. First, relatively little empirical work seems to have been done on sex and race differences in EI dimensions (Joseph and Newman 2010: 71). In fact, when considering gender differences in their review of the psychometrical properties of a trait EI questionnaire, Mikolajczak, Luminet et al. (2007: 348) find significant gender differences on scores, and strongly recommend that research be undertaken into potential biases in test construction. In their study of leadership self-efficacy, Villanueva and Sánchez (2007) 
explored the relationship between trait EI and leadership with a sample of 217 university students of psychology - of the sample, $83 \%$ were women. Results showed a significant difference between men and women trait EI scores, and the authors concede that gender may have played a role and influenced specific behaviours in the study. It is therefore key that gender differences be taken into account in the establishment of norms and in the interpretation of scores.

A second related limitation concerns sample size and composition. Samples are sometimes predominantly composed of students (e.g. Mikolajczak, Luminet et al. 2007; Villanueva and Sánchez 2007) and it is argued that future work would benefit from replicating results with larger and more heterogeneous samples drawn from a wider range of occupations (Nelis, Kotsou et al. 2011). In addition, studies often restrict range, especially regarding age, and so results have to be interpreted with caution (Mikolajczak, Luminet et al. 2007). According to Petrides (2009: 99), theoretically-driven research that emphasizes replication and explanation is needed and, as emotions are just one domain of personality, it is necessary to extend trait EI theory to encompass other domains (e.g. social, personal).

A third limitation to trait EI studies reviewed here is the tendency to rely on self-report instruments, which can be inaccurate and subject to response biases. According to Mavroveli and Sánchez-Ruiz (2011: 113) these are not problems unique to trait EI measures, and using self-reports is "based on the notion that one's reports on their intra- and interpersonal qualities are intrinsically meaningful and exert a notable influence on individuals' behaviours." Nonetheless, contextual factors and other variables need to be taken into account alongside trait EI scores. Mikolajczak and Luminet (2008: 1451) suggest the use of physiological indicators and/or neuroimaging techniques in conjunction with trait EI measures to remove biases associated with self-report instruments.

The use of translations of trait EI measures could also be problematic. Despite their frequent use (e.g. Mikolajczak, Bodarwé et al. 2010; Villanueva and Sánchez 2007; Zampetakis and Moustakis 2011) concerns remain as to whether cultural differences affect the way a trait is expressed. In their study, Zampetakis and Moustakis (2011: 87) explain that Greek native speakers translated the self-report measures they used, and that back translations revealed that "the translation had worked quite well and that the wording held similar connotations." This statement is hardly confidenceinspiring, and more attention is required in this area to ascertain the effectiveness of testing participants from different cultural backgrounds.

In addition to the above limitations, it could be argued that rare mention is made in trait EI literature of ethical approval procedures, debriefing participants, or obtaining informed consent. Nonetheless, despite these drawbacks, trait EI research shows promising results and remains the only account in the field that departs from the idea that EI is only beneficial, addressing the undesirable effects that it can manifest in certain contexts (Petrides, Vernon et al. 2011: 39).

In the next section, a brief overview will be provided of recent studies that have made use of trait EI measurements in higher education contexts specifically, and two studies of relevance to translation and interpreting (T\&I) focusing on academic performance and languages will be discussed. 


\section{Emotional Intelligence, Confidence, and Language Learning}

Psychology-based research on EI in higher education contexts has mostly focused on the relationship between EI and academic performance. For example, studies making use of both ability and trait measures have found that EI can predict the performance of undergraduate students on a single task (Lam and Kirby 2002) and that the EI of teams of students can predict their performance at the initial stages of a project (Jordan, Ashkanasy et al. 2002). More recently, studies have started to combine and triangulate EI questionnaires with other psychometric instruments and performance-related data (e.g. grades) to obtain more robust and trustworthy findings.

Petrides and Frederickson (2011) recently used performance-based criteria in conjunction with personality measures to find that aspects of trait EI predispose school children towards being generally confident, and that the propensity to be confident about achieving goals that are valuable to them is highly motivational and results in superior academic performance. Another recent study on scholastic achievement carried out by Mavroveli and Sánchez-Ruiz (2011) combined self-report measures with objective criteria, i.e. data on pupils' achievement in mathematics, reading and writing. Their results suggest that higher trait EI scores were implicated in improved performance in some subjects although the association between trait EI and academic achievement is still unclear (Mavroveli and Sánchez-Ruiz 2011: 126). In an earlier study, Mavroveli, Petrides et al. (2009) consciously employ a multimethod strategy for triangulation purposes. These authors acknowledge that the trait EI construct's direct impact on academic achievement is unclear, but that it is possible that the effects of trait EI may vary across educational levels as well as academic subjects. In their study of trait EI profiles of students from different university faculties, Sánchez-Ruiz, Pérez-González et al. (2010) argue that there is strong evidence supporting the view that students in different academic subjects have different personality profiles, and that there is an interaction between gender and faculty. They highlight that there are statistically significant differences in trait EI amongst students. For example, social science and arts students scored higher than technical studies students in Emotionality (Sánchez-Ruiz, Pérez-González et al. 2010: 54). The authors argue that establishing trait EI profiles across faculties can help achieve congruence between students' personalities and their chosen academic field, thus facilitating their academic achievement.

In what follows, two recent studies are presented which have made use of trait EI measurements in higher education contexts, focusing more specifically on academic performance and languages. These studies are not meant to be representative, but to demonstrate to those working, teaching and researching in the field of translation and interpreting the potential that studying EI can have for understanding performance.

In their study of the role of trait EI in academic performance and in deviant behaviour at school, Petrides, Frederickson et al. (2004) find that trait EI is significantly related to scholastic achievement, with important implications for low IQ pupils. The study is a comprehensive multivariate investigation based on a large sample, several different academic subjects, and multiple criteria. The relationship between trait EI and scholastic achievement is investigated with different psychometric tests, e.g. the TEIQue, the Eysenck Personality Questionnaire, the Verbal 
Reasoning Test, and data from national examinations in various academic subjects. Results clearly indicate that, in a sample of 650 pupils, various types of anxiety, stress, and emotional deficits negatively affect scholastic achievement, and that "trait EI seems differentially implicated in academic performance across the various subjects considered, with its effects being comparatively pronounced for English and overall GCSE (General Certificate of Secondary Education) performance and negligible for maths and science" (Petrides, Frederickson et al. 2004: 287). The authors argue that what they call "high trait EI" is conducive to improved performance in GCSE examinations, perhaps because it enables students to cope better with emotional stress and anxiety. Salovey, Bedell et al. (1999: 141) also argue that individual emotional competencies, i.e. how individuals perceive, express, understand, and manage emotional phenomena, influence responses to emotional arousal and, as a result, play a significant role in coping processes.

Petrides, Frederickson et al.'s 2004 study is significant for TS in two ways. Firstly, it highlights a link between performance and stress/anxiety, and suggests that trait EI might have a more prominent impact on the academic performance of students when the demands of a situation tend to outweigh their intellectual resources. The results are in line with those of other studies that corroborate the link between trait EI and coping with stress (e.g. Ciarrochi, Deane et al. 2002; Mikolajczak, Nelis et al. 2008; Mikolajczak, Roy et al. 2009). This finding is clearly relevant for translation and interpreting students, as managing the uncertainty inherent to translation can be quite stressful and impact on problem-solving (Tirkkonen-Condit 1997; Fraser 2000). Studies of interpreter performance have highlighted the impact of stress on the quality of performance and the need for successful coping mechanisms. (Seleskovitch 1978; Henderson 1987; Moser-Mercer 2008; Timarová and Salaets 2011). It could be hypothesized that translating and interpreting students with high trait EI - as measured by self-report instruments - are therefore also likely to perform successfully in certain translation or interpreting tasks where coping with emotional stress and anxiety is a necessity. The second relevant finding from this study for TS is the pronounced effect of trait EI for performance in English. It can be hypothesized that, in the UK, students performing well in the National Curriculum subject of English (whether at GCSE or A-level) will have acquired - and be able to successfully apply - skills in reading and writing that will hold them in good stead should they wish to pursue a degree or career in translation. Petrides, Frederickson et al. (2004: 287) observe that "trait EI may influence scholastic attainment by conferring a selective advantage for certain academic subjects that require consideration of affectrelated issues (English literature, arts, design, etc.)." Translation and interpreting have been considered as affect-related subjects by many (Jääskeläinen 1999; Hansen 2005; Bontempo and Napier 2011), which suggests the potential for trait EI to be a factor in T\&I performance.

Another study of interest to the translating and interpreting community is the work of Dewaele, Petrides et al. (2008) on the effects of trait emotional intelligence and sociobiographical variables on communicative anxiety and foreign language anxiety among multilinguals. In addition to employing the trait EI test TEIQue, the study uses a questionnaire to take account of a number of extra variables, such as age, gender, education level, number of languages known, age of onset of acquisition, context of acquisition, frequency of use etc. The results of their study are therefore 
quite complex and best interpreted in the context of their own analysis. However, one can extract from their discussion some noteworthy findings. Results show that out of the 464 multilingual individuals in the study, those with higher than average levels of trait EI suffered significantly less from communicative and foreign language anxiety, and that a higher level of self-perceived proficiency in a language (i.e. confidence in one's proficiency) was also linked to lower levels of anxiety (Dewaele, Petrides et al. 2008: 936). According to the authors (2008: 947), findings are significant and consistently show that people with high trait EI, measured with the TEIQue, have the lowest levels of communicative and foreign language anxiety, as assessed in five different situations (speaking with friends, colleagues, strangers, on the phone, and in public). Dewaele, Petrides et al. believe that the robustness of the results calls for follow-up studies, due to the fact that observed patterns of associations strongly suggest that trait EI might be a personality variable partially determining communicative/foreign language anxiety.

Here again, the findings are highly pertinent for T\&I. Firstly, the observed link between high levels of trait emotional intelligence and low levels of anxiety in certain language learning situations is particularly relevant for interpreters who need to be able to cope with their anxiety when speaking in public. If trait EI plays a role in communicative anxiety, then it clearly needs to be further researched in the context of translator and interpreter training. The second relevant finding is that having high levels of confidence in one's proficiency in a language reduces levels of anxiety. The authors observe that self-perceived speaking proficiency provided them with a rough indication of oral proficiency, and that a strong self-belief in the ability to regulate stress levels and to express oneself clearly might well lead to lower levels of both communicative and foreign language anxiety (2008: 947, 951). ${ }^{1}$ From this, one can conclude that actively nurturing self-perception and self-belief amongst our students could well contribute to the making of successful professionals.

In this paper, I am focusing more specifically on trait EI measures due to the greater empirical support they have attracted (Petrides 2010) and because it is my belief that non-cognitive emotion-related dispositions should be studied alongside cognitive abilities in translation process research. However, some studies that have made use of measures based on ability models have also found positive associations between EI and academic performance (see Di Fabio and Palazzeschi 2009), and between EI and care-centred or affect-related subjects (e.g. Zysberg, Levy et al. 2011; Kafetsios, Maridaki-Kassotaki et al. 2009). Despite the well-known drawbacks (further discussed in section 6) of employing questionnaires to obtain data, it is interesting to note that a number of findings are potentially very interesting for the study of T\&I, e.g. a relationship between emotional intelligence and coping mechanisms, a possible link between high trait EI and success in affect-related subjects, a correlation between self-confidence and anxiety levels. These findings could usefully be reflected upon in the context of translator and interpreter training, and merit further investigation.

\section{Emotional Intelligence and Translation Studies}

As mentioned earlier, the role of personal and emotional characteristics in translation and interpreting performance has been acknowledged for some time. Being able to appraise and communicate one's own and other people's emotions is a key aspect of 
intercultural communication, and therefore a key skill for translators and interpreters. Along with being a competent linguist, a translator arguably needs to mediate effectively between cultures, to understand a target reader's needs, expectations, and how to communicate a source author's message in a successful way to target readers, or to a target audience in an interpreter's case. Being able to recognize what a client, author or reader feels or requires, and finding ways to handle and transfer their perspectives is necessary for successful translation/interpreting performance and part of what psychologists call emotional intelligence. In today's world, where borders are disappearing and communities are increasingly multicultural, it is clear that translators and interpreters have a key role to play in building bridges between cultures and in mediating between speakers of different languages. The capacity of translators to understand and transfer sensitive and context-bound information, to accurately reflect the meaning of source culture texts, and to have the necessary interpersonal skills to adapt to different working situations are all acknowledged as key skills of competent translation professionals (National Occupational Standards in Translation 2007). ${ }^{2}$ The need for competent, sensitive and culturally-aware translators is also acknowledged by the European Commission Directorate-General for Translation. In their published list ${ }^{3}$ of essential competencies for professional translators, a number of interpersonal and intercultural skills are included, such as adaptability to new situations, ability to self-evaluate and knowing how to interact with different communities. These skills and attitudes relate to the concept of emotional intelligence as defined in personality psychology, and are clearly of increasing importance to professional bodies. It therefore seems likely that exploring the emotional intelligence of translators and interpreters could add something to our understanding of their working processes. In turn, this information could have important repercussions on - and feed into - the ways translators and interpreters are currently being trained.

One area where the importance of personal qualities in translation performance has perhaps been more obvious is within the field of literary translation, where discussions of translator style and individual characteristics are prominent (Munday 2008b; Winters 2009; Saldanha 2011). Many have also discussed the links between translation and creativity, highlighting the fact that literary translators are required to possess a creative streak for the production of successful target texts (Jones 2006; Lin 2006; Ellender 2006). In the introduction to their book entitled Translation and Creativity - Perspectives on Creative Writing and Translation Studies (2006), Manuela Perteghella and Eugenia Loffredo discuss the relationship between translation and creative writing and the newly scrutinized agency of the translator as a reader-creator and as self-writer; these authors exhort readers to rethink translation in terms of a creative writing practice, and suggest that creative writing has become "the next contender field promising an insight into the process of translation" (2006: 2). In their view, the psychology of creative writing is arguably one area where creative writing research might provide insight into the translation process.

In fact, research in the field of creative writing has generated a number of interesting findings on the role and impact of emotions and affect on the writing process. A number of studies (Barron 1969; Pourjalali, Skrzynecky et al. 2009; Perry 2009; Waitman and Plucker 2009) have found evidence that successful writers share certain personality traits. In the 1960s, the Institute for Personality Assessment and Research 
(IPAR) at the University of California (Berkeley) conducted a large study investigating the personalities of creative writers. They asked 56 outstanding creative writers to undergo a battery of tests (Piirto 2009), including the popular personality test known as the Myers-Briggs Type Indicator (MBTI) and discovered that a great majority of these authors shared an intuitive trait on the MBTI scale. Other studies (Barron 1969; 1995; Piirto 2009) have since confirmed this correlation between success in creative writing and possessing an intuitive personality trait. Interestingly, the MBTI function of intuition has been found to be significantly and positively related to higher levels of emotional intelligence (e.g. Higgs 2001). This correlation between high EI and high levels of creativity amongst writers is in line with findings from studies which indicate a much greater likelihood amongst this population of suffering from affective disorders, depression and anxiety (Pourjalali, Skrzynecky et al. 2009), often thought to be the result of intense sensitivity, deep empathy and other emotion-related attributes (Piirto 2009: 16-17). According to Russ, "the creative writing process involves cognitive, affective and personality processes within an individual that are involved in the creative act" and "individuals who are high on some of these processes will have a higher likelihood of producing a creative product" (2009: 248). Creative writing research has therefore produced evidence that individuals with high EI are more likely to produce creative written work, and it would not be inconceivable that high levels of EI might also have an impact on the creative potential of literary translators.

If there are certain emotional and personality-related attributes (e.g. intuition, sensitivity, empathy) that successful creative writers have been found to share, there may possibly also be certain attributes that successful literary translators may also share. In her article on the interaction of cognition with emotion in the processing of textual material, Davou (2007: 45) further highlights the links between creativity and emotion by suggesting that creativity may be a product of the different emotional significance that stimulates different thoughts to different persons. Differences in levels of creativity amongst translation students or practitioners might conceivably be linked to the different emotional significance that a text might hold for each of them. Successful translators have sometimes been described as emotionally engaged individuals (Fraser 1996: 95) who derive personal and contextual meanings from texts (Boase-Beier 2006: 53) and create interpersonal relationships with source text authors and assumed target text readers (Jääskeläinen 1999: 224). Different texts are also likely to elicit different emotional responses from translators, and a legal translation will not have the same potential for emotivity than, for example, translating a love poem. As such, the role that EI plays in the process will vary and different levels of EI are required from translators depending on text-types. According to Joseph and Newman (2010: 69) "individuals with high emotion regulation ability [...] perform especially well in jobs that require high emotional labour.” The implication for T\&I is that the translation of texts with high emotive potential is likely to be more successfully undertaken by an emotionally intelligent translator, but that texts with low emotive potential do not have the same requirement, as they rely less on the ability of the translator to regulate and manage emotions.

As previously indicated, research in TS has for some time indicated a potential relationship between emotional phenomena, creativity, and translation competence. Researchers' hypotheses in this respect perhaps deserve to be investigated more 
comprehensively, and this is an avenue for further research. Studying whether there may be correlations between emotional intelligence and translating or interpreting competence is a controversial enterprise but, as Pourjalali, Skrzynecky et al. (2009: 35) argue in relation to the links between creative writing and affective disorders, scholars should not shy away from examining and questioning this topic for fear of causing offence.

Although studies in non-cognitive individual differences are relatively few and far between in TS, there is evidence of explorative work currently being undertaken which attempts to borrow measures from the field of psychology to better understand translating and interpreting processes. This recent work is testimony to an expansion of the scope of translation research and sheds light on the value of understanding the emotional intelligence and individual differences of translators and interpreters. An interesting and first of its kind study in the field of interpreting has recently been conducted by Karen Bontempo. This researcher from Macquarie University is studying aspects of personality in sign language interpreting, and is seeking to identify which personality factors might be predictive of competent performance in signed language interpreters (Bontempo 2009; ${ }^{4}$ Bontempo and Napier 2011). Bontempo and Napier argue that individual personality differences relate to outcomes at work, that attention needs to be paid to both general cognitive ability and personality factors, and that "to concentrate research efforts on the cognitive factors that may predict performance in a profession is neglectful of the range of affective factors that have implications for the psychology of work" (Bontempo and Napier 2011: 87). Bontempo (2009) argues that there is renewed interest in evaluating the characteristics, personal qualities, and traits necessary for success in a signed language interpreter education programme, and that research points to the potential role of personality in successful occupational performance. She designed two studies of Auslan/English interpreters that made use of different psychological measurements focusing on a number of aspects of personality-related individual differences, including self-efficacy, negative affectivity, and self-esteem. Findings demonstrate that personality has an impact on interpreters' perceptions of competence (Bontempo 2009). More specifically results show that emotional stability, i.e. an individual's ability to manage life events and emotions (Newsome, Day et al. 2000: 1008), is a predictor of interpreter competence. However, those high in negative affectivity, i.e. the disposition to experience aversive emotional states such as anxiety (Watson and Clark 1984) were found to be less competent in making effective use of positive coping resources. Results of Bontempo's 2009 study are noteworthy in the sense that they "provide support for the emerging picture of a relationship between personality and work performance of signed language interpreters" and they indicate the presence of a link between emotional factors and interpreter competence, even suggesting that "if selecting for success, select individuals who are conscientious and emotionally adjusted" (Bontempo 2009). In a subsequent publication, Bontempo and Napier (2011) report in more detail on their efforts to gauge both sociological and psychological variables amongst 110 accredited signed language interpreters in Australia. The researchers compared personal parameters (e.g. interpreting experience, qualifications, etc.) with opinions and attitudes about linguistic skills, competence, knowledge, as well as some self-reporting personality measures and other background information (Bontempo and Napier 2011: 93). Results complement prior work and demonstrate that people with high levels of 
negative affectivity reported lower levels of competence as interpreters, that the dimension of emotional stability is key as a predictor of interpreter's self-perceived competence, and that personality impacts on interpreters' self-perceptions of competence (Bontempo and Napier 2011: 98). This rare exploration of interpreters' personality features and personal qualities further supports the necessity of studying the relationship between T\&I and personality psychology, and emotional self-perceptions more specifically.

Another study using self-report measures to explore attitudinal profiles of student translators and interpreters was recently undertaken by Rosiers, Eyckmans et al. (2011). Their investigation of individual difference variables led them to obtain information regarding linguistic self-confidence, motivation and language anxiety. Their comparative study of translating and interpreting students' profiles produced a number of interesting findings, for example that interpreting students rate their communicative competence higher than translating students and that there is a significant difference between both groups in the self-perception of global linguistic skills, i.e. that translating students experience more language anxiety than interpreting students, and that interpreting students have generally higher linguistic self-confidence with regard to their communicative skills and global linguistic competences (Rosiers, Eyckmans et al. 2011). Although not a study of emotional traits as such, this research on translators' and interpreters' personality characteristics, self-perceptions and attitudes is certainly innovative and revealing in terms of the broad range of personal and individual attributes that can impact on a translator or interpreters' performative behaviour.

In translation process research, a few studies have explored non-cognitive psychological and behavioural processes. In my 2009 article, I list some of the pioneering research in this area, such as Lörscher's study of translators' performances and strategies (1991), Tirkkonen-Condit's work on how translators manage uncertainty and ambiguity when translating (1997), and Fraser's investigation of levels of confidence in high and low risk-takers (2000). Despite not always drawing on psychological constructs as understood in the field of personality psychology, these (and subsequent) process studies are particularly valuable as they serve to highlight the significance of studying personal and individual traits of translators and interpreters.

One such study presents a strong case for building a bridge with the psychological construct of EI. My doctoral work (2007) investigated the effects of personality features on the performance of twenty French to English student translators while they worked on the translation of a short literary piece. The study aimed to demonstrate the influence of personalities and individual differences during translation, and to better understand how attitudinal behaviours affected the loss or gain of certain elements during the process of translating. As part of the methodology employed to obtain personality-related data on student translators, a version of the above-mentioned MBTI personality measure was used. Results indicated a potential correlation between success in the task and the presence of an intuitive trait amongst successful participants, generally perceived by an increased sensitivity to target readership requirements during the translation process. The fact that some of the students' success in the task was correlated with a strong element of intuition in their personality type is particularly interesting if we recall the finding that successful creative writers are "distinctly more intuitive than oriented to sense experience" 
(Piirto 2009: 7) and if we take the view that translation is "a mode of writing comparable to the traditional ones" (Perteghella and Loffredo 2006: 5), with translators often described as creative writers in their own right. In my study, self-perceived intuition and emotional traits were found to impact positively on translation performance, suggesting that successful and creative literary translators might also be distinctly intuitive and emotionally intelligent.

Studies briefly reviewed in this section highlighted the value of studying personal and emotional aspects of translators and interpreters. In the field of creative writing, we have seen that various psychometric measures have already been employed within process studies to shed light on aspects of creativity and competence. It is my contention that empirical studies in TS would also benefit from further incorporating noncognitive psychology-based concepts and measures in their work. It is important to remember that process research conducted to date has not always delivered consistent results and has involved relatively small samples of participants, rendering it difficult to generalize findings. The use of psychometric testing to tap into the feelings and emotions of translators and interpreters, alongside other methodologies, may go some way towards providing a level of consistency and validity to empirical studies in TS. In the next section, some concrete ways in which EI can be studied in TS research will be provided.

\section{Recommendations for Investigating EI in Future TS Research}

Some pioneering studies have started to make use of available tools from educational and personality psychology to test 'soft skills' amongst interpreters and translators (e.g. Timarová and Salaets 2011). However, EI has not - to my knowledge - been investigated thus far, and researchers may well wonder how best to scientifically investigate the topic of EI, i.e. which methods are the most appropriate to employ in order to uncover correlations between levels of emotional intelligence and, for instance, aspects of interpreter or translator performance.

In order to establish a basis for scientific investigation, my first recommendation is to explore available psychometric tools already developed for this purpose, as collaborative work with scholars in the field of psychology adds rigour to our attempts to "cut across boundaries" (Chesterman 2005, cited in Munday 2008a: 198). The construct of EI has already generated a significant body of research and issues of validity, reliability, factor structures and convergence have been discussed at length, resulting in two favoured, widely marketed and commonly used EI instruments for each school of thought. A review of the literature suggests that proponents of measuring EI as a cognitive-emotional ability, or form of intelligence, have generally employed the MSCEIT, or Mayer-Salovey-Caruso Emotional Intelligence Test (Mayer, Salovey and Caruso 2002). Researchers interested in the subjective nature of emotions and personality facets related to affect will often choose to operationalize trait EI with the TEIQue, or Trait Emotional Intelligence Questionnaire (Petrides 2009a). The latter covers the sampling domain of trait EI comprehensively (Petrides, Pita et al. 2007), was translated in over 20 languages, and is available in several forms (e.g. an adolescent version). In addition, for those interested in using trait EI measures, the research team that created the TEIQue family of measures have made these available free of charge for academic research on their programme Website. ${ }^{5}$ Both the 
MSCEIT and TEIQue are well-established measures, and TS researchers interested in further exploring either cognitive-emotional abilities or personality facets relating to affect could usefully incorporate these in their empirical study designs. There is increasing acknowledgement in TS of the advantages that an interdisciplinary approach brings, such as sensitizing scholars to questions not normally asked, or helping to interpret and explain the object of study (Brownlie 2008: 335). Nonetheless, concern has also been raised regarding the importing of concepts and methodologies from another discipline at a superficial level (Chesterman 2005, cited in Munday 2008a: 197), and thorough research into psychological concepts and methods adopted is warranted, alongside close collaboration with experts in the field of enquiry.

My second recommendation for investigating the EI of translators and interpreters is to reflect carefully on one's research aim and objectives, and decide on the most appropriate method or combination of methods to apply. Although this may seem obvious, different methodologies will be required depending on what is to be studied. A scholar wishing to understand potential links between levels of trait EI and literary translation performance may want to test published literary translators' EI with the TEIQue and compare results with those of professional non-literary translators. In this way, it would be possible to test the hypothesis that literary translators may have higher levels of trait EI than other professional translators. A scholar wanting to find out whether people with higher levels of EI are naturally drawn to a career in literary translation and/or whether students develop their EI over the course of a literary translation programme could test students' EI at the start and at the end of a professional literary translation MA programme. Results could also be compared with those of students on non-literary translation programmes. Another idea would be to carry out a comparative study of professional and trainee literary translators' EI to better understand the personality profile of a literary translator. Amongst other benefits, employing the TEIQue instrument in these cases would enable the production of statistical data, something likely to add an element of accuracy and reliability to this type of research. However, trait and ability instruments are not the only appropriate ways to investigate the emotional intelligence of translators and interpreters, and it would be unwise to rely entirely on these tools. Petrides, Frederickson et al. suggest that "research on trait EI is likely to benefit from an effort to present potential processes that may provide explanations for empirical results" [my emphasis] and that "trait EI is useful if it is judged primarily on the basis of what it explains, and not on the basis of what it predicts" (Petrides, Frederickson et al. 2004: 289). Whereas TS scholars have increasingly sought to bring objectivity to their research and to use scientific measures that are accurate, precise, reliable and valid, it would seem that the tradition in psychology of employing mainly positivist methods is raising as many questions as it answers. Using a mixedmethod approach for studying the EI of translators and interpreters, with a focus on both the process and the product, will produce rich narratives and, in many cases, be a more fruitful method of investigation than the sole use of a self-report questionnaire. For example, a scholar aiming to explore in a group of students a potential correlation between levels of trait EI and the quality of literary translations could request that the students undertake a translation task while thinking aloud and/or an in-depth interview, in addition to the completion of an EI test. In his discussion of EI measurement, Fineman makes the following argument: 
What we do, think and feel can be regarded as interpenetrative, context-bound and fluid [...] emotion's potential multifacetedness suggests that any one approach to understanding 'it' will be just that - one approach. It is necessarily partial, meaningful only in terms of the philosophy that informs it, the medium through which it is conveyed and the receiving audience. (Fineman 2004: 721)

\section{Conclusion}

In this paper, an attempt was made to highlight the value of exploring individual and emotional traits of translators and interpreters, and emotional intelligence more specifically. A number of studies from both psychology and TS were discussed, and recommendations were made regarding adequate methodology to employ for the future study of EI in translation and interpreting studies. Recent research on EI and on translators' and interpreters' soft skills has demonstrated the influence of affective factors on aspects such as performance, thus making a strong case for investigating emotional intelligence to gain a deeper understanding of translation and interpreting processes.

According to Timarová and Salaets (2011: 32) the "born or made" debate has definitely shifted towards "made," but doubts remain as to whether anyone can be trained as an interpreter. In the same way, it could be said that although there may not be a magic profile of the emotionally intelligent translator or interpreter who will excel in all aspects of their work, there may be a number of personality attributes that will hold a person in good stead for a career in T\&I. This line of research might offer clues about boosting student motivation and enhancing translator and interpreter training mechanisms.

Emotional intelligence researchers consider that EI is "useful for organizing a body of research that focuses on effectiveness in the context of emotions and emotionally charged thoughts" and that it has the "potential to be relevant to every aspect of people's lives" (Ciarrochi 2006: 254, 259). Amongst the different skills valued by translator and interpreter professional associations and clients, effectiveness in the communication and handling of emotional information and emotionally charged thoughts is an important and necessary one for competent performance. An important discovery in the study of trait EI is that there are situations in which possessing high trait EI is not beneficial. A number of studies (Petrides and Furnham 2003; Sevdalis, Petrides et al. 2007; Nelis, Quoidbach et al. 2009) have found that high trait EI scores can have maladaptive outcomes, with participants showing greater sensitivity and mood deterioration in certain affect-laden contexts than their low trait EI counterparts. In this instance, it could be argued that translators or interpreters with high trait EI might suffer from emotion interference and/or intense negative affect when dealing with disturbing material, for example when translating a rape deposition or interpreting in highly emotive situations, for example in an assignment involving asylum seekers. How translators and interpreters can learn to handle these situations and enhance their competence in these areas should therefore be the object of further research.

Although it can be surmised that decision processes for both translating and interpreting are influenced by emotional factors, particularly if we take into account recent work in brain research demonstrating that experience and emotion can never 
be removed from thoughts (Damasio 2003), it can also be assumed that the activities of translating and interpreting require different emotional competencies and skills. In addition, the different types of translations (e.g. technical, literary) and interpreting situations (e.g. conference, community) will necessitate specific skills in the perception, processing, regulation, and utilization of emotional information that are unique to each activity. Exploring emotion identification and emotion management abilities of translators and interpreters in these different contexts would therefore shed light on their significance for task performance.

Very recently, an attempt was made to improve levels of EI and make use of EI development methods (Nelis, Quoidbach et al. 2009). The study in question was the first to test in practice the impact of a theoretically-based training programme in EI by encouraging 37 participants to apply in their daily lives what was taught during formal sessions where techniques were provided to enhance various EI skills. Lectures, role-plays, group discussions, readings and personal diaries were all methods employed alongside a global trait EI measure and a battery of other psychometric tests. Results indicated that, as opposed to the control group, participants who had undergone the training scored significantly higher on trait EI and showed substantial improvement in emotion identification/perception and emotion management (Nelis, Quoidbach et al. 2009: 40) both of which are important translating and interpreting competences. In addition, it is noteworthy that positive changes remained significant in the long-term, implying that focused training can have real effects on behaviour modification. As Bontempo and Napier suggest (2011: 99), incorporating trait awareness into training would be very useful "given the broader evidence pointing to these aspects of personality as relevant for effective occupational performance." Aspects of emotional and individual differences include self-esteem, stress management, emotion perception and expression, empathy, social awareness, assertiveness, adaptability and self-motivation, amongst others. These aspects are clearly relevant for the practice of translation and interpreting and it is felt that emotional intelligence research can provide an additional framework for our investigations into the reasons why translators and interpreters act and behave the way they do.

\section{NOTES}

1. As highlighted by Bontempo and Napier (2011), literature in the field of foreign language learning also corroborates the link between anxiety and a negative impact on language learning and success in second language acquisition, and the impact of different language learning tasks on a students' self-belief and self-confidence, e.g. Gregersen and Horwitz 2002; Dörnyei 2005.

2. Cilt, The National Centre for Languages (2007): National Occupational Standards in Translation. Visited on 15 July 2011, <http://www.cilt.org.uk/home/standards_and_qualifications/ uk_occupational_standards/translation.aspx>.

3. EMT EXPERT GROUP (2009): Visited on 15 July 2011, <http://ec.europa.eu/dgs/translation/ programmes/emt/key_documents/emt_competences_translators_en.pdf $>$.

4. Bontempo, Karen (2009): Interpreter Personality: Unpacking individual differences in performance in sign language interpreters, unpublished. ASLIA National Conference. Melbourne, 26-28 August 2009.

5. Petrides, Kostantinos V. (2008; Last update: 2013): London Psychometric Laboratory at UCL. Visited on 15 August 2011, <http://www.psychometriclab.com>. 


\section{REFERENCES}

Alvstad, Cecilia, Hild, Adelina and Tiselius, Elisabet, eds. (2011): Methods and Strategies of Process Research. Amsterdam: John Benjamins Publishing Company.

BARron, Frank (1969): The psychology of the creative writer. Explorations in Creativity. 43(12):69-74.

Barron, Frank (1995): No Rootless Flower: an Ecology of Creativity. Cresskill: Hampton Press.

BERgEn, David (2009): The role of metacognition and cognitive conflict in the development of translation competence. Across Languages and Cultures. 10(2):231-250.

BOASE-BEIER, Jean (2006): Loosening the grip of the text: Theory as an aid to creativity. In: Manuela Perteghella and Eugenia Loffredo, eds. Translation and Creativity - Perspectives on Creative Writing and Translation Studies. London and New York: Continuum, 47-56.

BonTEMPo, Karen and NAPIER, Jemina (2011): Evaluating emotional stability as a predictor of interpreter competence and aptitude for interpreting. Interpreting. 13(1):85-105.

Brackett, Mark and Geher, Glen (2006): Measuring emotional intelligence: Paradigmatic diversity and common ground. In: Joseph Ciarrochi, Joseph Forgas and John Mayer, eds. Emotional Intelligence and Everyday Life. New York: Psychology Press, 27-51.

BROWNLIE, Siobhan (2008): Resistance and non-resistance to boundary crossing in translation research. Target. 20(2):333-347.

Ciarrochi, Joseph (2006): The current state of emotional intelligence research: Answers to some old questions and the discovery of some new ones. In: Joseph Ciarrochi, Joseph Forgas and John MAYer, eds. Emotional Intelligence in Everyday Life. New York: Psychology Press, 251-260.

Ciarrochi, Joseph, Deane, Frank and Anderson, Stephen (2002): Emotional intelligence moderates the relationship between stress and mental health. Personality and Individual Differences. 32:197-209.

Ciarrochi, Joseph, Forgas, Joseph and Mayer, John, eds. (2006): Emotional Intelligence in Everyday Life. New York: Psychology Press.

Chesterman, Andrew (1997): Memes of Translation. Amsterdam: John Benjamins Publishing Company.

Chesterman, Andrew (2005): Towards consilience? In: Karin Ajjmer and Cecilia Alvstad, eds. New Tendencies in Translation Studies. Göteborg: Göteborg University, 19-28.

Chmiel, Agnieszka (2010): Interpreting studies and psycholinguistics: A possible synergy effect. In: Gyde Hansen, Daniel Gile and Nike Kocijančič Pokorn, eds. Why Translation Studies Matters. Amsterdam: John Benjamins Publishing Company, 223-236.

Cooper, Colin (2002): Individual Differences. London: Hodder Arnold.

Cordovil De Sousa Uva, Mariana, De Timary, Philippe, Cortesia, Marie et al. (2009): Moderating effect of emotional intelligence on the role of negative affect in the motivation to drink in alcohol-dependent subjects undergoing protracted withdrawal. Personality and Individual Differences. 48(1):16-21.

Damasio, Antonio (2003): Looking for Spinoza. Joy, Sorrow and the Feeling Brain. New York: Harvest Book Harcourt, Inc.

DAvou, Bettina (2007): Interaction of emotion and cognition in the processing of textual material. Meta. 52(1):37-47.

Dewaele, Jean-Marc, Petrides, K. V. and Furnham, Adrian. (2008): Effects of trait emotional intelligence and sociobiographical variables on communicative anxiety and foreign language anxiety among multilinguals: A review and empirical investigation. Language and Learning. 59:911-960.

Di Fabio, Annamaria and Palazzeschi, Letizia (2009): An in-depth look at scholastic success: Fluid intelligence, personality traits or emotional intelligence? Personality and Individual Differences. 46:581-585.

DöRNYEI, Zoltan (2005): The psychology of the language learner: Individual differences in second language acquisition. Mahwah: Lawrence Erlbaum. 
ELLENDER, Claire (2006): Re-rendering the dialogic writings of Claude Sarraute: Translate or recreate? In: Ian Kemble and Carol O'Sullivan, eds. Creativity in Translation - Proceedings of the 5th Portsmouth Translation Conference. Portsmouth: University of Portsmouth, 6-14.

Fineman, Stephen (2004): Getting the measure of emotion - And the cautionary tale of emotional intelligence. Human Relations. 57(6):719-740.

Fiori, Marina and AntonAKis, John (2011): The ability model of emotional intelligence: Searching for valid measures. Personality and Individual Differences. 50:329-334.

Fraser, Janet (1996): Mapping the process of translation. Meta. 41(1):84-96.

FrASER, Janet (2000): What do real translators do? Developing the use of TAPs from professional translators. In: Riitta JäÄSKELÄINEN and Sonja TirkKonen-Condit, eds. Tapping and Mapping the Processes of Translation and Interpreting. Amsterdam: John Benjamins Publishing Company, 111-123.

GARDNER, Howard (1983): Frames of mind. New York: Basic Books Inc.

Gregersen, Tammy and Horwitz, Elaine (2002): Language learning and perfectionism: Anxious and non-anxious language learners' reactions to their own oral performance. The Modern Language Journal. 86(iv):562-570.

HAnsen, Gyde (2005): Experience and emotion in empirical translation research with think aloud and retrospection. Meta. 50(2):511-521.

Hatzidaki, Anna (2007): The Process of Comprehension from a Psycholinguistic Approach Implications for Translation. Meta. 52(1):13-21.

Henderson, John (1987): Personality and the Linguist. Bradford: Bradford University Press.

Higgs, Malcolm (2001): Is there a relationship between the Myers-Briggs type indicator and emotional intelligence? Journal of Managerial Psychology. 16(7):509-533.

Hitrikoski, Juhani (2002): Transitive verbs of emotion in Finnish and English. In: Merja Koskela and Nina Pilke, eds. Erikoiskielet ja käannösteoria. Vaasa: Vaasan yliopisto, 108-121.

HöNIG, Hans (1998): Complexity, contrastive linguistics and translator training: Comments on responses. In: Christina SCHäFfner, ed. Translation and Quality. Philadelphia: Multilingual Matters, 83-89.

HubsCher-DAvidson, Séverine (2007): An Empirical Investigation into the Effects of Personality on the Performance of French to English Student Translators. Doctoral thesis, unpublished. Bath: University of Bath.

Hubscher-Davidson, Séverine (2009): Personal diversity and diverse personalities in translation: A study of individual differences. Perspectives: Studies in Translatology. 17(3):175-192.

JäÄskeläinen, Riitta (1999): Tapping the Process: An Explorative Study of the Cognitive and Affective Factors Involved in Translating. Joensuu: University of Joensuu.

JAEger, Audrey (2003): Job competencies and the curriculum: An enquiry into emotional intelligence in graduate professional education. Research in Higher Education. 44(6):615-639.

Jones, Francis (2006): Unlocking the black box: Researching poetry translation processes. In: Manuela Perteghella and Eugenia Loffredo, eds. Translation and Creativity Perspectives on Creative Writing and Translation Studies. London/New York: Continuum, 59-74.

Jordan, Peter, Ashranasy, Neil, Härtel, Charmine, et al. (2002): Workgroup emotional intelligence: Scale development and relationship to team process effectiveness and goal focus. Human Resource Management Review. 12:195-214.

Joseph, Dana L. and Newman, Daniel A. (2010): Emotional intelligence: An integrative metaanalysis and cascading model. Journal of Applied Psychology. 95(1):54-78.

Kafetsios, Konstantinos, Maridaki-Kassotaki, Aikaterini, Zammuner, Vanda, et al. (2009): Emotional intelligence abilities and traits in different career paths. Journal of Career Assessment. 17(4):367-383.

Kaufman, Alan and Kaufman, James (2001): Emotional intelligence as an aspect of general intelligence: What would David Wechsler say? Emotion. 1:258-264. 
LAM, Laura and Kirby, Susan (2002): Is emotional intelligence an advantage? An Exploration of the Impact of Emotional and General Intelligence on Individual Performance. Journal of Social Psychology. 142:133-143.

LeE, Hyeseung (2003): Analysis of Russian-Korean translation of emotion metaphor. Conference Interpretation and Translation. 5(1):183-200.

Lin, Xavier (2006): Creative translation, translating creatively: A case study on aesthetic coherence in Peter Stambler's Han Shan. In: Manuela Perteghella and Eugenia Loffredo, eds. Translation and Creativity - Perspectives on Creative Writing and Translation Studies. London and New York: Continuum, 97-108.

LÖrscher, Wolfgang (1991): Translation Performance, Translation Process, and Translation Strategies. Tübingen: Gunter Narr.

Matthews, Gerald, Deary, Ian and Whiteman, Martha, eds. (2003): Personality Traits. $2^{\text {nd }}$ ed. Cambridge: Cambridge University Press.

Mavroveli, Stella, Petrides, Kostantinos V., Sangareau, Yolanda et al. (2009): Exploring the relationships between trait emotional intelligence and objective socio-emotional outcomes in childhood. British Journal of Educational Psychology. 79:259-272.

Mavroveli, Stella and Sánchez-Ruiz, María José (2011): Trait emotional intelligence influences on academic achievement and school behaviour. British Journal of Educational Psychology. 81:112-134.

MAYER, John (2006): A new field guide to emotional intelligence. In: Joseph Ciarrochi, Joseph Forgas and John MAYER, eds. Emotional Intelligence in Everyday Life. New York: Psychology Press, 3-27.

Mayer, John and Ciarrochi, Joseph (2006): Introduction. In: Joseph Ciarrochi, Joseph Forgas and John Mayer e, eds. Emotional Intelligence in Everyday Life. New York: Psychology Press, xiii-xx.

Mayer, John, Salovey, Peter and Caruso, David (2002): Mayer-Salovey-Caruso Emotional Intelligence Test (MSCEIT): User's Manual. Toronto: Multi-Health Systems.

Mikolajczak, Moïra, Bodarwé, Kerrin, Laloyaux, Olivier et al. (2010): Association between frontal EEG asymmetries and emotional intelligence among adults. Personality and Individual Differences. 48(2):177-181.

Mikolajczak, Moïra and Luminet, Olivier (2008): Trait emotional intelligence and the cognitive appraisal of stressful events: An exploratory study. Personality and Individual Differences. 44:1445-1453.

Mikolajczak, Moïra, Luminet, Olivier, Leroy, Cecile et al. (2007): Psychometric properties of the trait emotional intelligence questionnaire: Factor structure, reliability, construct, and incremental validity in a french-speaking population. Journal of Personality Assessment. 88(3):338-353.

Mikolajczak, Moïra, Menil Clémentine and Luminet, Olivier (2007): Explaining the protective effect of trait emotional intelligence regarding occupational stress: Exploration of emotional labour processes. Journal of Research in Personality. 41:1107-1117.

Mikolajczak, Moïra, Nelis, Delphine, Hansenne, Michel et al. (2008): If you can regulate sadness, you can probably regulate shame: Associations between trait emotional intelligence, emotion regulation and coping efficiency across discrete emotions. Personality and Individual Differences. 44(6):1356-1368.

Mikolajczak, Moïra, Petrides, Kostantinos V., Coumans, Nathalie et al. (2009): The moderating effect of trait emotional intelligence on mood deterioration following laboratoryinduced stress. International Journal of Clinical and Health Psychology. 9(3):455-477.

Mikolajczak, Moïra, Roy Emmanuel, Verstrynge, Valérie et al. (2009): An exploration of the moderating effect of trait emotional intelligence on memory and attention in neutral and stressful conditions. British Journal of Psychology. 100:699-715.

Moнammady, Ranjbar (2008): The translation problems of emotional internal body part metaphors in both Persian and English. Translation Studies in the New Millennium. 6(21):8-38. 
Moser-Mercer, Barbara (2008): Skill Acquisition in Interpreting. The Interpreter and Translator Trainer. 2(1):1-28.

Munday, Jeremy (2008a): Introducing Translation Studies: Theories and Applications. $2^{\text {nd }}$ ed. London and New York: Routledge.

Munday, Jeremy (2008b): Style and Ideology in Translation. London and New York: Routledge.

Nelis, Delphine, Kotsou, Ilios, QuoidBaCH, Jordi et al. (2011): Increasing emotional competence improves psychological and physical well-being, social relationships, and employability. Emotion. 11(2):354-366.

Nelis, Delphine, Quoidbach, Jordi, Miкоlajczak, Mö̈ra et al. (2009): Increasing emotional intelligence: (How) is it possible? Personality and Individual Differences. 47:36-41.

Newsome, Shaun, Day, Arla and Catano, Victor (2000): Assessing the predictive validity of emotional intelligence. Personality and Individual Differences. 29:1005-1016.

Papavassiliou, Périclès (2007): Traductologie et sciences cognitives: une dialectique prometteuse. Meta. 52(1):29-36.

Perry, Susan (2009): Writing in Flow. In: Scott Kaufman and James Kaufman, eds. The Psychology of Creative Writing. Cambridge: Cambridge University Press, 213-224.

Perteghella, Manuela and Loffredo, Eugenia, eds. (2006): Translation and Creativity - Perspectives on Creative Writing and Translation Studies. London and New York: Continuum.

Petrides, Kostantinos V. (2009a): Technical manual for the Trait Emotional Intelligence Questionnaires (TEIQue). London: Psychometric Laboratory.

Petrides, Kostantinos V. (2009b): Psychometric properties of the Trait Emotional Intelligence Questionnaire (TEIQue). In: Con Stough, Donald H. Saklofske, and James D. A. PArker, eds. Advances in the Measurement of Emotional Intelligence. New York: Springer, 85-101.

Petrides, Kostantinos V. (2010): Trait emotional intelligence theory. Industrial and Organizational Psychology: Perspectives on Science and Practice. 3:136-139.

Petrides, Kostantinos V. and Frederickson, Norah (2011): An application of belief-importance theory in the domain of academic achievement. British Journal of Educational Psychology. 81: 97-111.

Petrides, Kostantinos V., Frederickson, Norah and Furnham, Adrian (2004): The role of trait emotional intelligence in academic performance and deviant behaviour at school. Personality and Individual Differences. 36(1):277-293.

Petrides, Kostantinos V. and Furnham, Adrian (2001): Trait emotional intelligence: Psychometric investigation with reference to established trait taxonomies. European Journal of Personality. 15:425-448.

Petrides, Kostantinos V. and Furnham, Adrian (2003): Trait emotional intelligence: Behavioural validation in two studies of emotion recognition and reactivity to mood induction. European Journal of Personality. 17:39-57.

Petrides, Kostantinos V., Pita, Ria and Koкkinaki, Flora (2007): The location of trait emotional intelligence in personality factor space. British Journal of Psychology. 98:273-289.

Petrides, Kostantinos V., Vernon, Philip A., Aitken Schermer, Julie et al. (2011): Trait emotional intelligence and the Dark Triad traits of personality. Twin Research and Human Genetics. 14:35-41.

Pirrto, Jane (2009): The personalities of creative writers. In: Scott Kaufman and James Kaufman, eds. The Psychology of Creative Writing. Cambridge: Cambridge University Press, $3-22$.

Pourjalali, Samaneh, Skrzynecky, E. M. and Kaufman, James (2009): The creative writer, dysphoric rumination, and locus of control. In: Scott KaUfman and James Kaufman, eds. The Psychology of Creative Writing. Cambridge: Cambridge University Press, 23-40.

Publilius, Syrius (c. 100 BC/1961/2004): "Sententiae." In: John Duff and Arnold Duff, eds. Minor Latin Poets. Cambridge, MA: Harvard University Press. Retrieved from: Peter Salovey, Marc Brackett and John Mayer, eds. Emotional Intelligence - Key Readings on the Mayer and Salovey Model. New York: Dude Publishing, 1-27. 
Quoidbach, Jordi and Hansenne, Michel (2009): The impact of trait emotional intelligence on nursing team performance and cohesiveness. Journal of Professional Nursing. 25(1):23-29.

Rosiers, Alexandra, Eyckmans, June and Bauwens, Daniel (2011): A story of attitudes and aptitudes?: Investigating individual difference variables within the context of interpreting. Interpreting. 13(1):53-69.

Russ, Sandra (2009): Pretend play, emotional processes, and developing narratives. In: Scott Kaufman and James Kaufman, eds. The Psychology of Creative Writing. Cambridge: Cambridge University Press, 247-263.

Saldanha, Gabriela (2011): Translator style: methodological considerations. The Translator. 17(1):25-50.

Salovey, Peter, Bedell, Brian and Mayer, John (1999): Coping Intelligently - Emotional Intelligence and the Coping Process. In: Rick SNY DeR, ed. Coping: The Psychology of What Works. New York: Oxford University Press, 141-164.

Salovey, Peter and Mayer, John (1990/2004): Emotional intelligence. Imagination, Cognition, and Personality. In: Peter Salovey, Marc Brackett and John Mayer, eds. Emotional Intelligence - Key Readings on the Mayer and Salovey Model. New York: Dude Publishing, $1-27$.

Sánchez-Ruiz, María José, Hernández-Torrano, Daniel, Pérez-Gonzáles, Juan Carlos et al. (2011): The relationship between trait emotional intelligence and creativity across subject domains. Motivation and Emotion. 35:461-473.

SÁnchez-Ruiz, María José, Pérez-Gonzáles, Juan Carlos and Petrides, Kostantinos V. (2010): Trait emotional intelligence profiles of students from different university faculties. Australian Journal of Psychology. 62(1):51-57.

Seleskovitch, Danica (1978): Interpreting for International Conferences. Washington: Pen and Booth.

Sevdalis, Nick, Petrides, Kostantinos V. and Harvey, Nigel (2007): Trait emotional intelligence and decision-related emotions. Personality and Individual Differences. 42(7):1347-1358.

Shreve, Gregory and Angelone, Erik, eds. (2010): Translation and cognition. American Translators Association Scholarly Monograph Series 15. Amsterdam: John Benjamins Publishing Company.

Timarová, Šárka and Salaets, Heidi (2011): Learning styles, motivation and cognitive flexibility in interpreter training: Self-selection and aptitude. Interpreting. 13(1):31-52.

TirkKonen-Condit, Sonja (1997): Who verbalises what: A linguistic analysis of TAP texts. Target. 9(1):69-84.

Van Rooy, David and Viswesvaran, Chockalingam (2004): Emotional intelligence: A metaanalytic investigation of predictive validity and nomological net. Journal of Vocational Behavior. 65(1):71-95.

Venuti, Lawrence (1995): The Translator's Invisibility. London and New York: Routledge.

Villanueva, José J. and Sánchez, José C. (2007): Trait emotional intelligence and leadership self-efficacy: their relationship with collective efficacy. The Spanish Journal of Psychology. 10(2):349-357.

Waitman, Grace and Plucker, Jonathan (2009): Teaching writing by demythologizing creativity. In: Scott Kaufman and James Kaufman, eds. The Psychology of Creative Writing. Cambridge: Cambridge University Press, 287-315.

Watson, David and Clark, Lee (1984): Negative affectivity: the disposition to experience aversive emotional states. Psychological Bulletin. 96(3):465-490.

Williams, Catrin, Daley, David, Burnside, Elizabeth, et al. (2009): Measuring Emotional Intelligence in preadolescence. Personality and Individual Differences. 47:316-320.

Williams, Catrin, Daley, David, Burnside, Elizabeth, et al. (2010): Can trait Emotional Intelligence and objective measures of emotional ability predict psychopathology across the transition to secondary school? Personality and Individual Differences. 48:161-165.

WinTERs, Marion (2009): Modal particles explained: How modal particles creep into translations and reveal translators' styles. Target. 21(1):74-97. 
WitTwer, Michael (2007): Emotion and translation: using the example of popularising medical texts in paediatrics. In: Khurshid AHMAD and Margaret Rogers, eds. Evidence-based LSP: Translation, Text and Terminology. Bern: Peter Lang, 345-356.

Zampetakis, Leonidas A. and Moustakis, Vassilis (2011): Managers' trait emotional intelligence and group outcomes: The case of group job satisfaction. Small Group Research. 42(1):77-102.

Zysberg, Leehu, Levy, Anat and Zisberg, Anna (2011): Emotional Intelligence in Applicant Selection for Care-Related Academic Programs. Journal of Psychoeducational Assessment. 29(1):27-38. 